\title{
Temptation in economic decision making: effects of immediate reward and reward-cues
}

\author{
This article was published in the following Dove Press journal: \\ Neuroscience and Neuroeconomics \\ 15 March 2013 \\ Number of times this article has been viewed
}

\section{Eva Woelbert Rainer Goebel \\ Department of Cognitive Neuroscience, Maastricht University, Maastricht, The Netherlands}

Correspondence: Eva Woelbert PO Box 616, 6200 MD Maastricht, The Netherlands

Tel +3 I 433884507

Fax +3| 43388 4I 25

Email eva.woelbert@maastrichtuniversity. $\mathrm{nl}$

submit your manuscript $\mid$ www.dovepress.con

Dovepress

http://dx.doi.org/1 0.21 47/NAN.\$24226
Abstract: Immediate exposure to reward or reward-predicting stimuli (cues) influences behavior. For example, chips placed right in front of us are likely to get eaten even if we wish to lose weight or don't actually like chips so much. In this paper we review evidence that shows that immediate exposure to reward and the presence of reward-cues can change economic behavior across various decision domains. Reward cues lead to less patient intertemporal choice, seem to increase risk aversion, and bias consumer choice. This may explain various, at first glance very different, behavioral phenomena, such as dynamic inconsistency, the certainty effect, and the endowment effect. We suggest that immediacy in time, certainty, and physical possession all create immediacy to a rewarding outcome that might bias choice in a similar way as other reward-predicting stimuli.

Keywords: immediacy, certainty, proximity, valuation, choice, Pavlovian cues

\section{Introduction}

Environmental stimuli can exert powerful control over behavior. Relapses of drug addicts often occur when the person finds themselves in an environment in which they used to consume drugs, or when confronted with drug-related materials. ${ }^{1}$ More commonly experienced, food-related stimuli such as the smell of freshly baked cookies or the sight of a hamburger not only make our mouths water, but also stimulate our appetite and increase subsequent food intake. ${ }^{2}$

Drug abuse and overeating have received considerable attention in psychology, neuroscience, and economics since they constitute major public health problems, but also because they seem at odds with self-interest and are often explicitly regretted. It is puzzling why people engage in these behaviors nevertheless, especially under the assumption that stable, well-defined preferences guide behavior. While each of these different disciplines has described and analyzed this phenomenon within their own framework, there is a common underlying spirit in their explanations.

From a psychological perspective, the effect of contextual cues on behavior may be seen as a manifestation of Pavlovian and instrumental learning. The smell of cookies has frequently preceded the consumption of cookies and thus leads to an expectation of cookies and activates behaviors leading to consumption. ${ }^{3}$ Neuroscientific data suggests that dopamine plays an important role in the underlying neural processes. ${ }^{4}$ Firing of dopaminergic cells increases in response to reward-predictive stimuli such as the sight of a hamburger. ${ }^{5,6}$ At the same time, dopamine is involved in motivation and action selection. ${ }^{7-10}$ Assuming that these two functions interact somehow, the occurrence of a reward-predictive stimulus might enhance the motivation to pursue a 
particular reward. ${ }^{11}$ Similar ideas have been formalized by economists, assuming that consumption in the presence of specific cues may be (or seem) more valuable to the organism than in the absence of the stimulus. ${ }^{12-14}$

A situation that contains reward cues and leads to behavior that is at odds with long-term goals resulting from rational deliberation, such as a healthy lifestyle, is frequently described as "tempting." 15 There is accumulating evidence that the stimulus environment not only influences decisions about primary needs like food, or physiological stimulation from drugs, but a wider range of economically relevant decisions including intertemporal choice over money, decisions under uncertainty, and consumer choice. In this review article we summarize evidence on the effects of immediate exposure to reward and reward-predicting stimuli on economic decision making. We then revisit literature on well-documented biases in decision making like certainty effects and the endowment effect and explore whether they might be driven by a similar mechanism.

\section{Immediate exposure to reward and reward predicting stimuli affects economic decisions}

\section{Impatient intertemporal decisions}

Intertemporal choices require trade-offs between outcomes that vary in value, but also occur at different moments in time. Typical intertemporal choices we encounter in everyday life are savings decisions and health-oriented behavior such as exercising, smoking, and food choices. Healthy behavior is often associated with some immediate inconvenience, such as foregoing desert, whereas the benefits will only become apparent weeks or years after these decisions. Similarly, saving money requires refraining from spending money in the present in order to be able to spend it at some point in the future. In experiments, such decisions are often mimicked by giving subjects the choice between receiving a smaller, but sooner reward, and a larger, but delayed one - typically money. While many interesting behavioral phenomena have been observed in intertemporal decision making, we focus on evidence that shows that exposure to reward-related stimuli decreases patience in intertemporal choice. For a more general overview on the intertemporal choice literature there exist several comprehensive reviews. ${ }^{16-18}$

Perhaps the most comprehensive evidence on determinants of intertemporal choice stems from an instructive series of experiments on delay of gratification in children. ${ }^{19}$ Children at preschool age performed intertemporal choices about food and toy rewards under different conditions. Typically, children were left alone in a room with a small quantity of the reward. Children were then told that if they waited for some time without consuming the reward or calling for the experimenter they would receive a larger amount of the same reward. If exposure to reward-predicting stimuli influences intertemporal choice, the physically immediate reward should decrease the children's ability to wait. Indeed, waiting times decreased when the reward was put immediately in front of the children. Interestingly, waiting times decreased monotonically with the amount of reward that the children were immediately exposed to. ${ }^{20}$ Thus, being physically close to a reward did not only decrease the ability to delay gratification, but the strength of this effect also depended on the quantity of reward the subjects were exposed to. A similar effect was observed when children were not physically exposed to the reward, but instructed to think about the appetitive properties of the reward. Likewise, the effect of a physically present reward could be diminished by instructing the children to distract themselves from the appetitive nature of the stimulus, for example by focusing on non-rewarding properties of the stimulus. These findings suggest that reward exposure leads to less patient intertemporal choices, and that this effect is mediated by attention to the appetitive properties of the available reward. ${ }^{19}$

Based on these findings, Van den Bergh et $\mathrm{al}^{21}$ hypothesized that a general appetitive motivational state leads to impatience in intertemporal choice. They exposed men to erotic cues, followed by a series of intertemporal choices involving money, candy bars, and soft drinks. Relative to a control group that saw neutral stimuli, these subjects decided less patiently. Thus, exposure to erotic cues increased preference for the smaller, sooner reward across various types of reward. This effect was only present for those men who scored higher on a self-report measure of individual sensitivity to rewards, suggesting that the effect of erotic stimuli on discounting was indeed mediated by an appetitive motivational state. Likewise, Wilson and Daly found that exposure to pictures of attractive faces of the opposite sex, but also attractive cars, increased discounting of future rewards relative to exposure to unattractive faces and cars. ${ }^{22}$

In sum, exposure to reward and reward-related stimuli results in less patient intertemporal choices. This effect seems to be mediated by an appetitive motivational state.

\section{Risk averse choices}

Decisions across various life domains involve uncertainty. For example, when investing money, making decisions about study, or accepting a job offer the decision maker is uncertain 
which of several possible outcomes - some more favorable than others - will occur. Expected utility theory provides a powerful normative framework for decision making under uncertainty, but many situations have been described where people's actual behavior deviates from the predictions of the theory. ${ }^{23}$

The role of the stimulus environment has received less attention in research on decisions under uncertainty than in intertemporal choice. However, one recent experiment suggests that both reward- and punishment-related stimuli can influence choices between certain and uncertain gains. In a Pavlovian conditioning phase, Guitart-Masip et $\mathrm{al}^{24}$ trained subjects to learn that certain artificial visual stimuli were always followed by a gain and certain others always followed by a loss. Afterwards, subjects made a series of binary choices between sure outcomes and gambles. The stimuli from the conditioning phase (conditioned stimuli $[\mathrm{CS}]$ ) were visually presented together with these choices, but were completely irrelevant to the decision and not informative of the outcome. Nevertheless, they influenced choice behavior. When a stimulus that had previously been predictive of gains (CS+), but was then completely irrelevant, was visually presented during choice, people showed an enhanced preference for certainty. In the presence of a stimulus previously predictive of losses (CS-), people made more risky choices. Since in this study the conditioned stimulus was always visually underlying the sure option it seems that choices were biased towards the appealing conditioned stimulus and away from the unappealing one. Alternatively, it could be that the mere presence of a reward-predicting stimulus led to higher preference for certainty, independent of the location of the stimulus. Choices in accordance with this effect went along with higher activity in the amygdala, and the ventral striatum. ${ }^{24}$ This is consistent with the current understanding of the amygdala as a brain region that is central to the influence of emotional stimuli on behavior. ${ }^{25}$ These data suggest that irrelevant stimuli which are associated with reward and punishment can influence decisions under uncertainty.

\section{Consumer decisions}

Knowing the value a person places on an item is of great interest in decision-making research, marketing, and public policy. It is often measured as the maximum amount a person is willing to pay to obtain an item. A recent experiment investigated systematically whether willingness to pay (WTP) could be influenced by the way items were presented to the subjects. ${ }^{26}$ Bushong et $\mathrm{al}^{26}$ elicited WTP for both snack-food items and trinkets, while varying the display format of the items. Subjects who had the items physically in front of them reported higher WTP than subjects who saw text or image displays. Interestingly, there was no effect on rating how much one liked the item, and WTP was increased across the whole liking range; that is, even for disliked items, the physical presence of the item increased WTP. In order to test competing explanations for this observation, the authors performed a series of control experiments: combining the image and text displays with pretasting a small amount of the food item did not elevate WTP, suggesting that the effect is also not attributable to differences in experienced utility or information about the item. Finally, the authors observed that placing a fully transparent plexiglass barrier between the subject and the food item resulted in WTP comparable to the text and picture conditions. Thus, the effect of the physically present item on WTP was diminished by a plexiglass barrier, although the actual distance and information available to the subject was held constant. This shows that the physical presence of the item has a strong effect on WTP, but only if it is within easy reach of the subject. The authors suggest that when physically immediate, an item functions like a CS, which, in turn, promotes behaviors that lead to obtaining the item and thus increase WTP.

That CS can indeed affect simple consumer decisions has been demonstrated by Bray et al. ${ }^{27}$ Subjects first underwent a Pavlovian conditioning phase where they learned the association between specific visual stimuli (which then served as CS) and the delivery of a small quantity of a specific drink, like juice or chocolate milk. In a second, entirely independent phase, subjects were allowed to choose their drink out of two alternatives on every trial. In a third phase, subjects made these choices again, but were also shown one of the CS on each trial. The presence of a CS biased subjects' choices towards the drink that was associated with this stimulus. For example, subjects chose chocolate milk more often in the presence of a CS that has been associated with chocolate milk in the past. Relative to such cue-congruent choices, choices that were incongruent with the present CS were associated with lower activity in the ventrolateral putamen. Based on these findings, the authors suggest that a CS might automatically activate an action plan to obtain the associated outcome. Choosing an alternative outcome would then require suppression of these cue-triggered processes.

In sum, there is evidence from experiments across various decision domains that immediate exposure to reward or reward-predicting stimuli influences economic decisions: people decide less patiently, ${ }^{20-22}$ are more risk averse, ${ }^{24}$ and show higher $\mathrm{WTP}^{26}$ and biased choice ${ }^{27}$ when faced with reward-predicting stimuli. In the following we will explore whether some well-known biases in economic decisions 
could be explained by the fact that the decision situations in which they occur naturally entail greater immediacy to rewarding outcomes.

\section{Could immediacy to reward underlie biased economic decisions?}

According to standard economic theory, decisions should only depend on the likely outcomes they produce - and not on the elicitation procedure. ${ }^{16,28}$ Decades of research have shown, however, that decisions can be influenced by theoretically irrelevant aspects of the choice problem or the decision situation. . $32,29,30^{2}$

When deciding about future consequences, such as dieting or saving money, people tend to choose more patiently when all options concern outcomes in the future than when some outcomes are realized immediately and thus involve immediate gratification. ${ }^{16,31}$ Likewise, when deciding under uncertainty, people show a strong, disproportionate preference for certain outcomes when these are available. ${ }^{32-34} \mathrm{~A}$ third robust behavioral phenomenon in is the so-called endowment effect, or gap between willingness to pay and willingness to accept (WTA). Asking people how much compensation they demand to part with an object robustly yields higher value estimates than asking them how much they would be willing to pay to acquire the same object. ${ }^{29,35}$

The special appeal of immediately available reward relative to future reward is a popular explanation for biased decision making in intertemporal choice. Various, mostly unrelated explanations have been put forward to account for certainty effects and the endowment effect. In the light of the results summarized above we argue that these very different behavioral phenomena could, at least in part, all be driven by some form of immediacy to a rewarding outcome in the decision situation.

\section{Dynamic inconsistency}

Discounted utility theory, which is today the predominant normative framework for intertemporal choice, suggests that future rewards should be discounted at a constant rate. ${ }^{16,18,36}$ This implies that a person who prefers $€ 100$ now over $€ 150$ in 1 month will also prefer $€ 100$ in 1 year over $€ 150$ in 1 year and 1 month. Intertemporal choice experiments with both animals and humans have aimed at understanding how organisms actually decide between immediate and delayed rewards..$^{30,37}$ Many of these found that both animals and humans show a disproportionate preference for immediate rewards, which can result in choices that are dynamically inconsistent. ${ }^{31,38-42}$ For example, consider a subject who prefers a smaller amount of money that is delivered immediately after the experiment over a larger amount that is delivered with a delay. The same subject may prefer the larger, later reward when neither of the rewards is available immediately, although the amounts of reward, as well as the delay from the sooner to the later reward, are kept constant. ${ }^{31}$ Likewise, suppose that in January a person makes the plan to save the end-of-the-year bonus he or she will receive in December and invest it for 1 year to gain interest. When December comes and the bonus is immediately available, he or she might change this plan, and decide to spend the money right away on Christmas presents. However, under discounted utility theory, the decision situation in January is equivalent to the decision in December, and the change of plan is inconsistent. ${ }^{16,36}$ The fact that people make use of commitment devices, which make a change of plan impossible or very costly, provides compelling evidence that preferences are dynamically inconsistent at times, and that decision makers are aware of this. In the above example, the decision maker would prefer to commit to their saving plan in January in a way that makes it impossible or unappealing to change it - provided that they foresee the change of mind. Various forms of commitment devices have been described in the literature, ${ }^{16,43}$ and today their existence and popularity is evident in the internet. Several websites (eg, http://www.stickk.com/) allow users to commit to a goal and to determine a binding punishment in case of failing to reach the goal. Interestingly, the most popular goals that call for commitment devices seem to be saving money, exercising, sticking to a certain diet, and not smoking.

Many authors have explained such dynamic inconsistency in intertemporal decision making by assuming that immediacy in time - that is, "now" - is special, and that an immediately available reward is tempting and hard to resist. ${ }^{16,17,44}$ While this idea is intuitively appealing and fairly accepted, the question why immediately available reward might have this effect has only recently received more attention.

\section{Immediately available reward and brain activity}

Luo et $\mathrm{al}^{45}$ investigated whether brain activity during the anticipation of immediate monetary rewards differed from brain activity during the anticipation of delayed rewards. Each reward, consisting of a money amount available after a specified delay, was presented individually in a magnetic resonance imaging (MRI) scanner. Importantly, each subject performed a series of binary choices before the scanning session. Subjects' choices in this task were used to calibrate the amounts used during scanning such that immediate and delayed options were equally preferred by the individual. Despite this preference matching of the immediate and delayed options, the basal ganglia, the midbrain, and the anterior insula showed higher activity when immediate as 
opposed to delayed rewards were presented, and subjects responded faster during these trials. Previous studies using the same experimental task found that the activity level in these brain regions correlated with anticipated reward value..$^{46,47}$ The authors therefore suggest that immediate rewards elicit stronger reward anticipation than the preference-matched delayed rewards. Higher activity in reward-related brain regions for immediate versus delayed rewards was also reported by McClure et al, both for monetary and primary rewards, like juice and water. ${ }^{48,49}$

Although such differential brain activity is not unequivocally interpretable as stronger reward anticipation, other studies support the idea that immediate options induce disproportionately strong reward anticipation that may lead to strong preference for immediate reward, which can in turn be counteracted using cognitive control. Hariri et a ${ }^{50}$ measured individual discount rates using a behavioral delay discounting task. The same subjects also played a guessing task in the MRI scanner, which allowed measurement of blood oxygenation level-dependent (BOLD) signals in response to gains and losses. How strongly the ventral striatum reacted to gains relative to losses was associated with individual discount rates in the intertemporal choice task. That is, subjects that had a higher reactivity in this reward-sensitive brain region decided less patiently, which suggests a relation of neural reward sensitivity to discounting behavior.

Transcranial magnetic stimulation (TMS) allows to temporarily disrupt function in parts of the brain. Applying TMS over the left dorsolateral prefrontal cortex (DLPFC), a region implicated in cognitive control, Figner et al ${ }^{51}$ found a decrease in the proportion of patient choices specifically when an immediate reward was available. This indicates that the DLPFC contributes towards more patient decision making, but only when immediate rewards are available. The authors conclude that DLPFC activity in intertemporal choice represents self-control processes, counteracting the temptation of immediately available reward.

Taken together, these studies suggest that immediate rewards elicit disproportionately strong reward anticipation. The behavioral results summarized in the "Impatient intertemporal decisions" section demonstrate that exposure to appetitive cues results in less patient intertemporal choices. ${ }^{19,21}$ Thus, dynamically inconsistent intertemporal choices could be driven by an appetitive state that is induced by the prospect of immediate reward, but absent or weaker for the prospect of delayed reward.

\section{Certainty effects}

Many, though not all, deviations from expected utility theory arise when one available option involves outcomes that occur with certainty. ${ }^{32,34,52,53}$ That certain outcomes are different from probabilistic outcomes was first pointed out by Allais, ${ }^{32}$ who proposed two sets of choice problems to demonstrate that people show a disproportionate preference for certainty and violate predictions of expected utility theory:

1. The common consequence effect

(A) Certainty of 100 million

(B) $10 \%$ chance of 500 million; $89 \%$ chance of 100 million, $1 \%$ chance of nothing

(A') $11 \%$ chance of 100 million; $89 \%$ chance of nothing

(B') $10 \%$ chance of 500 million; $90 \%$ chance of nothing

2. The common ratio effect

(C) Certainty of 1 million

(D) $98 \%$ chance of 500 million; $2 \%$ chance of nothing

(C') $1 \%$ chance of 100 million; $99 \%$ chance of nothing

(D') $0.98 \%$ chance of 500 million; 99.02 chance of nothing.

Using problems with a similar structure, but with moderate gains, Kahneman and Tversky empirically confirmed that more people act more risk averse when there is a certain option available than when there is not. ${ }^{53}$ That is, (A) was preferred over (B) much more often than $\left(A^{\prime}\right)$ was preferred over $\left(B^{\prime}\right)$. Likewise $(C)$ was preferred more often than $\left(C^{\prime}\right)$, showing that a substantial number of people reverse their preference when there is no certain option available. Both are robust findings, and the common consequence effect has recently been replicated in a large representative sample with both real and hypothetical payoffs. ${ }^{33,54}$ Strong preference for certainty is apparent even when a given outcome is not actually certain at the time of decision making, but merely framed as certain by dividing a lottery into two or more stages. That is, an outcome that is certain, conditional on a first random event, is preferred over an outcome that has a conditional probability smaller than 1, giving rise to the so-called isolation effect..$^{53}$ Even more striking, when asked to assign a monetary value to a certain outcome and to a lottery ticket that would result in the same or a better outcome, people assign a higher monetary value to the certain outcome than to the lottery ticket. For example, people value a voucher for a dinner in a certain restaurant higher than they value a lottery over a voucher for the same or a better restaurant..$^{55}$ 


\section{Certainty as as form of immediacy}

While there is ample evidence that humans exhibit a strongly disproportionate preference for certain outcomes, there has been little consideration about why certainty is special. Here, we propose that certain outcomes are special because they are more immediate to the subject and easier to anticipate than uncertain outcomes. Any uncertain outcome involves a mechanism that resolves uncertainty and might lead to an unfavorable result. On the other hand, the only thing that separates the subject from an outcome offered with certainty is the subject's decision.

To see how reducing the probability of an outcome can indeed reduce immediacy of an outcome, consider the following experiment: ${ }^{56}$ subjects were given a simple intertemporal choice problem, having to decide between receiving

(A) 100 Dutch guilders (fl.) now, or

(B) fl. 110 in 4 weeks.

A different group of subjects was faced with a similar problem, but all outcomes were delayed by an additional 26 weeks (a so-called front-end delay). That is, for them the choice was between

(A') fl. 100 in 26 weeks, or

(B') fl. 110 in 30 weeks.

When there was no explicit uncertainty, ie, all outcomes were assigned probability 1 , there was a substantial difference between the two conditions. More subjects preferred (A) over (B) than there were subjects preferring $\left(\mathrm{A}^{\prime}\right)$ over $\left(\mathrm{B}^{\prime}\right)$. That is, the earlier of the two options was preferred more often when it was available immediately than when it was available in the future, although the delay between the early and the late option was 4 weeks in both cases. This provides strong evidence for the abovementioned dynamic inconsistency and temptation by the immediate option. Interestingly, the effect of the front-end delay was dramatically reduced when outcomes were not certain, but were all assigned a probability of 0.9 . When all outcomes occurred only with probability of 0.5 , (A) was chosen equally as often as ( $\left.\mathrm{A}^{\prime}\right)$. That is, when outcomes were sufficiently uncertain, subjects did not show any dynamic inconsistency. ${ }^{54,56}$

These and similar results have led researchers to note that uncertainty and delay have similar effects on behavior, and different interpretations for these similarities have been put forward. Some have argued that dynamic inconsistency arises due to the increased uncertainty associated with future outcomes, and, more generally, that delay discounting is a derivative of uncertainty inherent in the future. ${ }^{56,57}$ Others have argued that delay is psychologically more fundamental, as uncertainty frequently leads to omission of reward and thus results in experience of delay. ${ }^{58}$ Since behavioral evidence on the interaction of risk and delay is inconclusive, ${ }^{54,59}$ brain imaging studies have tried to resolve the question whether delay discounting and probability discounting are equivalent. Although decision making under risk and intertemporal choice invoked partially the same brain regions, clear distinctions in brain activity were also observed. Activity in the ventral striatum and the orbitofrontal cortex correlated with subjective value for both probabilistic and delayed rewards. ${ }^{60}$ Among others, the posterior parietal cortex, lateral prefrontal cortex, and anterior insula were found to be more involved in decision making under risk, whereas the lateral parietal cortex and posterior cingulate were preferentially active in intertemporal choice. ${ }^{60,61}$ Thus, it seems unlikely that delay discounting is fundamental to probability discounting, or vice versa.

Instead, choice behavior shows that both temporal immediacy and certainty contribute to inducing decision biases like the certainty effect and dynamic inconsistency. In many cases, both temporal immediacy and certainty are necessary to induce these biases..$^{54,56}$ Therefore, we suggest that uncertainty might reduce the immediacy to the offered reward in a similar manner as temporal delay does, without needing to assume that risk and delay are per se psychologically equivalent. Certain outcomes would then be disproportionately preferred because they are more immediate to the subject.

\section{Endowment effect}

A third prominent behavioral anomaly in economic decision making is the gap between valuations when elicited as WTP and WTA. For example, when subjects are endowed with a mug and asked for their WTA for selling the mug, they will typically state substantially higher valuations than subjects that are asked for their WTP for buying the same mug. ${ }^{35}$ Many behavioral studies of this "endowment effect" suggest that several factors, both cognitive and emotional, contribute to biasing the valuations of buyers and sellers in opposite directions. ${ }^{62-66}$ The endowment effect has also been observed in nonhuman primates ${ }^{67}$ which indicates that at least some of the contributing factors might be evolutionarily older than the emergence of private property rights. One circumstance that is frequently overlooked in endowment effect experiments is that elicitation of WTA naturally goes along with placing the item at stake physically close to the subject, whereas WTP elicitation does not.

Two studies have explicitly attended to the role of physical proximity in the endowment effect by manipulating physical proximity independently of legal ownership of the 
object. ${ }^{68,69}$ That is, one group of subjects was told that they now owned an item, but it was not given to them physically. Another group of subjects was physically given the item, but informed that it did not belong to them. Strikingly, both studies found that the physical possession of an object induced an increase in valuation and a reluctance to trade the object for an alternative. Being told that one owns the object, on the other hand, had no such effect. ${ }^{68,69}$ Thus, the physical possession of an item increased subjects' valuations, whereas legal ownership did not. This is in line with the findings of Bushong et $\mathrm{al}^{26}$ (see "Consumer decisions").

\section{Effects of endowment and physical proximity on brain activity}

Investigating the neural basis of the endowment effect, De Martino et $\mathrm{al}^{70}$ found that the BOLD response in both the orbitofrontal cortex and the dorsal striatum correlated with the subjective value of an item, irrespective of whether the subject was engaged in buying or selling the item. The endowment effect was evident in the activity pattern of the ventral striatum. That is, when subjects stated high selling prices or low buying prices, activity in the ventral striatum increased. These findings are in line with current understanding of the orbitofrontal and ventromedial prefrontal cortex encoding an abstract, possibly reference-independent, value signal ${ }^{71}$ and the ventral striatum encoding a reward prediction error. ${ }^{5,72}$

Evidence on the effects of physical proximity on brain activity in humans is very limited due to the substantial practical difficulties associated with bringing physical objects in the fMRI environment and in sight of the subject. Recent studies that have overcome this problem show that brain regions relevant for visuomotor control respond more strongly to objects within reach, as opposed to objects that are out of reach of the subject. ${ }^{73,74}$ That is, the brain seems to represent possible reaching targets constantly, even if reaching is not required by the task. The effect of physical proximity on valuation might thus arise from an interaction of constantly updated motor affordances with value computation processes.

\section{Conclusion}

There is ample evidence from both animals and humans that irrelevant stimuli can bias choice behavior if they have been associated with reward or punishment in the past. ${ }^{10,75,76}$ Recent experiments show that this is also the case for abstract economic decisions. When immediately exposed to reward or rewardpredicting stimuli, subjects make less patient intertemporal choices, are less risk averse in choice under uncertainty and are influenced in their consumer decisions. ${ }^{21,22,24,26,27}$ These findings constitute stimulus-induced, momentary changes in choice behavior that are at odds with rational deliberation and thus resemble effects of temptation.

Some of the most robust biases in economic decision making arise when there are options that are available immediately, occur with certainty, or are physically close to the subjects. Although clearly psychologically distinct, temporal immediacy, certainty, and physical proximity entail a form of immediacy to reward and might therefore act like reward-predicting stimuli and tempt the decision maker to choose an option they would not otherwise choose.

Understanding how immediacy to reward and exposure to reward-predicting cues influences valuation and choice could thus help to explain seemingly dissimilar decision biases and organize experimental results across various decision situations. Further, exploring the neural mechanisms underlying the effects of exposure to reward and rewardpredicting stimuli would contribute towards a more complete understanding of the neural mechanisms underlying decision making and thus help to improve prediction accuracy of economic models.

\section{Acknowledgments}

We thank Sanae Barth, Elena Cettolin, Joerg Gross, and Martin Strobel for helpful comments on earlier versions of the manuscript.

\section{Disclosure}

The authors report no conflicts of interest in this work.

\section{References}

1. Robbins TW, Everitt BJ. Drug addiction: bad habits add up. Nature. 1999;398:567-570.

2. Ferriday D, Brunstrom JM. How does food-cue exposure lead to larger meal sizes? Br J Nutr. 2008;100:1325-1332.

3. Balleine BW, Ostlund SB. Still at the choice-point: action selection and initiation in instrumental conditioning. Ann N Y Acad Sci. 2007; 1104:147-171.

4. Yun IA, Wakabayashi KT, Fields HL, Nicola SM. The ventral tegmental area is required for the behavioral and nucleus accumbens neuronal firing responses to incentive cues. J Neurosci. 2004;24(12): 2923-2933.

5. Bayer HM, Glimcher PW. Midbrain dopamine neurons encode a quantitative reward prediction error signal. Neuron. 2005;47(1): 129-141.

6. Schultz W, Dayan P, Montague PR. A neural substrate of prediction and reward. Science. 1997;275(5306):1593-1599.

7. O’Doherty J, Dayan P, Schultz J, Deichmann R, Friston K, Dolan RJ. Dissociable roles of ventral and dorsal striatum in instrumental conditioning. Science. 2004;304(5669):452-454

8. Kahnt T, Park SQ, Cohen MX, Beck A, Heinz A, Wrase J. Dorsal striatal-midbrain connectivity in humans predicts how reinforcements are used to guide decisions. J Cogn Neurosci. 2009;21(7):1332-1345.

9. Sharot T, Shiner T, Brown AC, Fan J, Dolan RJ. Dopamine enhances expectation of pleasure in humans. Curr Biol. 2009;19(24) 2077-2080 
10. Corbit LH, Janak PH, Balleine BW. General and outcome-specific forms of pavlovian-instrumental transfer: the effect of shifts in motivational state and inactivation of the ventral tegmental area. Eur J Neurosci. 2007;26(11):3141-3149.

11. Berridge KC, Robinson TE. Parsing reward. Trends Neurosci. 2003; 26(9):507-513.

12. Laibson D. A cue-theory of consumption. $Q J$ Econ. 2001;116(1): 81-119.

13. Bernheim BD, Rangel A. Addiction and cue-triggered decision processes. Am Econ Rev. 2004;94(5):1558-1590.

14. Loewenstein G. Out of control: visceral influences on behavior. Organ Behav Hum Decis Process. 1996;65(3):272-292.

15. Fishbach A, Friedman RS, Kruglanski AW. Leading us not unto temptation: momentary allurements elicit overriding goal activation. J Pers Soc Psychol. 2003;84.

16. Frederick $\mathrm{S}$, Loewenstein $\mathrm{G}, \mathrm{O}^{\prime}$ Donoghue T. Time discounting and time preference: a critical review. J Econ Lit. 2002;40(2):351-401.

17. Berns GS, Laibson D, Loewenstein G. Intertemporal choice - toward an integrative framework. Trends Cogn Sci. 2007;11(11):482-488.

18. Kalenscher T, Tobler PN. Interdisciplinary perspectives on decision making. Cogn Affect Behav Ne. 2008;8(4):345-347.

19. Mischel W, Shoda Y, Rodriguez ML. Delay of gratification in children. Science. 1989;244(4907):933-938.

20. Mischel W, Ebbesen EB. Attention in delay of gratification. J Pers Soc Psychol. 1970;16(2):329-337.

21. Van den Bergh B, Dewitte S, Warlop L. Bikinis instigate generalized impatience in intertemporal choice. J Consum Res. 2008;35(1): 85-97.

22. Wilson M, Daly M. Do pretty women inspire men to discount the future? P Roy Soc Lond B Bio. 2004;271 Suppl 4:S177-S179.

23. Tversky A, Kahneman D. The framing of decisions and the psychology of choice. Science. 1981;211(4481):453-458.

24. Guitart-Masip M, Talmi D, Dolan R. Conditioned associations and economic decision biases. Neuro Image. 2010;53(1):206-214.

25. Phelps E. Emotion and cognition: Insights from studies of the human amygdala. Annu Rev Psychol. 2006;57:27-53.

26. Bushong B, King LM, Camerer CF, Rangel A. Pavlovian processes in consumer choice: the physical presence of a good increases willingnessto-pay. Am Econ Rev. 2010;100(4):1556-1571.

27. Bray S, Rangel A, Shimojo S, Balleine B, O’Doherty JP. The neural mechanisms underlying the influence of pavlovian cues on human decision making. J Neurosci. 2008;28(22):5861-5866.

28. Mas-Colell A, Whinston MD, Green JR. Microeconomic Theory. 1st ed. New York: Oxford University Press; 1995.

29. Kahneman D, Knetsch JL, Thaler RH. Experimental tests of the endowment effect and the Coase theorem. J Polit Econ. 1990;98(6): 1325-1348.

30. Madden G, Bickel WK, editors. Impulsivity: The Behavioral and Neurological Science of Discounting. 1st ed. Washington, DC: American Psychological Association; 2009.

31. Kirby KN, Herrnstein RJ. Preference reversals due to myopic discounting of delayed reward. Psychol Sci. 1995;6(2):83-89.

32. Allais M. Le comportement de l'homme rationnel devant le risque: Critique des postulats et axiomes de l'ecole americaine. [The behavior of rational man under risk: a critique of the assumptions and axioms of the American school]. Econometrica. 1953;21:503-546. French.

33. Huck S, Müller W. Allais for all: revisiting the paradox in a large representative sample. J Risk Uncertainty. 2012;44:261-293.

34. Starmer C. Developments in non-expected utility theory: the hunt for a descriptive theory of choice under risk. J Econ Lit. 2000;38:332-382.

35. Knetsch JL. The endowment effect and evidence of nonreversible indifference curves. Am Econ Rev. 1989;79(5):1277-1284.

36. Samuelson P. A note on measurement of utility. Rev Econ Stud. 1937; 40:155-161.

37. Commons M, Mazur J, Nevin J, Rachlin H, editors. The Effect of Delay and Intervening Events on Reinforcement Value. Hillsdale, NJ: Lawrence Erlbaum Associates; 1987:5
38. Ainslie GW. Impulse control in pigeons. J Exp Anal Behav. 1974;21(3): 485-489.

39. Ainslie G, Herrnstein R. Preference reversal and delayed reinforcement. Learn Behav. 1981;9:476-482.

40. Green L, Fristoe N, Myerson J. Temporal discounting and preference reversals in choice between delayed outcomes. Psychon Bull Rev. 1994;1:383-389.

41. Loewenstein G, Thaler RH. Intertemporal choice. J Econ Perspect. 1997;3(4):181-193.

42. Green L, Estle S. Preference reversals with food and water reinforcers in rats. J Exp Anal Behav. 2003;79(2):233-242.

43. Ainslie G. Specious reward: a behavioral theory of impulsiveness and impulse control. Psychol Bull. 1975;82(4):463-496.

44. Laibson D. Golden eggs and hyperbolic discounting. $Q J$ Econ. 1997;112(2):443-477.

45. Luo S, Ainslie G, Giragosian L, Monterosso JR. Behavioral and neural evidence of incentive bias for immediate rewards relative to preference-matched delayed rewards. J Neurosci. 2009;29(47): $14820-14827$.

46. Knutson B, Taylor J, Kaufman M, Peterson R, Glover G. Distributed neural representation of expected value. J Neurosci. 2005;25(19): 4806-4812.

47. Knutson B, Fong G, Adams C. Dissociation of reward anticipation and outcome with event-related fMRI. Neuro Report. 2001;12(17): 3683-3687.

48. McClure SM, Laibson DI, Loewenstein G, Cohen JD. Separate neural systems value immediate and delayed monetary rewards. Science. 2004;306(5695):503-507.

49. McClure SM, Ericson KM, Laibson DI, Loewenstein G, Cohen JD. Time discounting for primary rewards. J Neurosci. 2007;27(21): 5796-5804.

50. Hariri AR, Brown SM, Williamson DE, Flory JD, De Wit H, Manuck SB. Preference for immediate over delayed rewards is associated with magnitude of ventral striatal activity. J Neurosci. 2006;26(51): 13213-13217.

51. Figner B, Knoch D, Johnson EJ, et al. Lateral prefrontal cortex and self-control in intertemporal choice. Nat Neurosci. 2010;13(5): 538-539.

52. Andreoni J, Sprenger C. Certain and uncertain utility: the Allais Paradox and five decision theory phenomena. Working Paper. 2010.

53. Kahneman D, Tversky A. Prospect theory: an analysis of decision under risk. Econometrica. 1979;47(2):263-291.

54. Weber BJ, Chapman GB. The combined effects of risk and time on choice: does uncertainty eliminate the immediacy effect? Does delay eliminate the certainty effect? Organ Behav Hum Dec. 2005;96(2): 104-118.

55. Gneezy U, List JA, Wu G. The uncertainty effect: when a risky prospect is valued less than its worst possible outcome. QJ Econ. 2006;121(4): 1283-1309.

56. Keren G, Roelofsma P. Immediacy and certainty in intertemporal choice. Organ Behav Hum Dec. 1995;63(3):287-297.

57. Epper T, Fehr-Duda H, Bruhin A. Uncertainty Breeds Decreasing Impatience: the Role of Risk Preferences in Time Discounting. Working Paper No. 412. Zurich: Institute for Empirical Research in Economics, University of Zurich; 2009. Available from: http://www.iew.uzh.ch/wp/ iewwp412.pdf. Accessed January 23, 2013.

58. Rachlin H, Raineri A, Cross D. Subjective probability and delay. J Exp Anal Behav. 1991;55(2):233-244.

59. Andreoni J, Sprenger C. Risk Preferences Are Not Time Preferences: Discounted Expected Utility with a Disproportionate Preference for Certainty. NBER Working Paper No. 16348. Cambridge, MA: National Bureau of Economic Research; 2010. Available from: http://www.nber. org/papers/w16348.pdf?new_window=1. Accessed August 7, 2012.

60. Peters J, Büchel C. Overlapping and distinct neural systems code for subjective value during intertemporal and risky decision making. J Neurosci. 2009;29(50):15727-15734. 
61. Weber BJ, Huettel SA. The neural substrates of probabilistic and intertemporal decision making. Brain Res. 2008;1234:104-115.

62. Johnson EJ, Häubl G, Keinan A. Aspects of endowment: a query theory of value construction. J Exp Psychol Learn. 2007;33(3):461-474.

63. Brenner L, Rottenstreich Y, Sood S, Bilgin B. On the psychology of loss aversion: possession, valence, and reversals of the endowment effect. J Consum Res. 2007;34(3):369-376.

64. Carmon Z, Ariely D. Focusing on the foregone: how value can appear so different to buyers and sellers. J Consum Res. 2000;27(3):360-370.

65. Lin CH, Chuang SC, Kao DT, Kung CY. The role of emotions in the endowment effect. J Econ Psychol. 2006;27(4):589-597.

66. Lerner JS, Small DA, Loewenstein G. Heart strings and purse strings: carryover effects of emotions on economic decisions. Psychol Sci. 2004;15(5):337-341.

67. Lakshminaryanan V, Chen MK, Santos LR. Endowment effect in capuchin monkeys. Philos Trans R Soc Lond B Biol Sci. 2008;363(1511): 3837-3844.

68. Reb J, Connolly T. Possession, feelings of ownership and the endowment effect. Judgm Decis Mak. 2007;2(2):107-114.

69. Knetsch JL, Wong WK. The endowment effect and the reference state: evidence and manipulations. J Econ Behav Organ. 2009;71(2): $407-413$
70. De Martino B, Kumaran D, Holt B, Dolan RJ. The neurobiology of reference-dependent value computation. J Neurosci. 2009;29(12): 3833-3842.

71. Levy DJ, Glimcher PW. The root of all value: a neural common currency for choice. Curr Opin Neurobiol. 2012;22(6):1027-1038.

72. Hare TA, O'Doherty J, Camerer CF, Schultz W, Rangel A. Dissociating the role of the orbitofrontal cortex and the striatum in the computation of goal values and prediction errors. J Neurosci. 2008;28(22): $5623-5630$.

73. Gallivan JP, Cavina-Pratesi C, Culham JC. Is that within reach? fMRI reveals that the human superior parieto-occipital encodes objects reachable by the hand. $J$ Neurosci. 2009;29(14):4381-4391.

74. Gallivan JP, McLean A, Culham JC. Neuroimaging reveals enhanced activation in a reach-selective brain area for objects located within participants typical hand workspaces. Neuropsychologia. 2011;49(13): 3710-3721.

75. Huys QJM, Cools R, Gölzer M, et al. Disentangling the roles of approach, activation and valence in instrumental and pavlovian responding. PLoS Comput Biol. 4, 2011;7(4):e1002028.

76. Holmes NM, Marchand AR, Coutureau E. Pavlovian to instrumental transfer: a neurobehavioural perspective. Neurosci Biobehav $R$. 2010;34(8):1277-1295.
Neuroscience and Neuroeconomics

\section{Publish your work in this journal}

Neuroscience and Neuroeconomics is an international, peer-reviewed, open access journal focusing on the identification of brain structures and measurement of neural activity related to behavior, behavioral predictions, and decision making in health and disease. The manuscrip management system is completely online and includes a very quick and

\section{Dovepress}

fair peer-review system. Visit http://www.dovepress.com/testimonials. php to read real quotes from published authors. 